\title{
Clinical Profile and Outcome of Mechanically Ventilated Children in a Pediatric Intensive Care Unit Surabaya
}

\author{
Qorri 'Aina ${ }^{1}$, Arina Setyaningtyas ${ }^{2 *}$, Atika $^{3}$ \\ ${ }^{1}$ Faculty of Medicine, Universitas Airlangga Surabaya \\ ${ }^{2}$ Department of Pediatrics, Faculty of Medicine, Universitas Airlangga, Surabaya, Indonesia - Dr. Soetomo General Hospital \\ Surabaya, Indonesia \\ ${ }^{3}$ Department Public Health and Preventive Medicine, Faculty of Medicine, Universitas Airlangga, Surabaya, Indonesia
}

\section{A R T I C L E I N F O}

\section{Article history:}

Received 21 September 2020

Received in revised form 27

October 2020

Accepted 29 October 2020

Available online 31 October 2020

Keywords:

Pediatric,

Ventilator,

Intensive Care

\section{*) Corresponding author:}

arinasetya@gmail.com

\begin{abstract}
A B S T R A C T
Introduction: Ventilator is used as one of the most frequent life-supportive technology in Pediatric Intensive Care Unit (PICU). There are only few studies from Asian Countries, especially Indonesia regarding the use of ventilator in PICU. The aim of this study was to describe the demographic, indications, length of use, complication, and outcome of patients with ventilator in PICU Dr. Soetomo Hospital, Surabaya.

Methods: This is a descriptive study. Collecting data was done retrospectively using medical records of patients using ventilator in PICU Dr. Soetomo General Hospital from January-December 2017 . Statistical analysed was performed using Microsoft Excel 2016

Results: 59 patients met the inclusion criteria. Of the 59 patients, 34 (57.63\%) were female and 27 (45.76\%) were infant (1-12 months). Common indication of ventilator were status epilepticus and shock that happened in $17(28.81 \%)$ patients. $44(74.58 \%)$ patient was using ventilator $>48$ hours. There are only 4 (6.78\%) of 59 patients that happened to had Ventilator Associated Pneumonia (VAP) as a complication of using ventilator. Mortality occurred in $40(67.80 \%)$ patients and mostly happened in female $(60 \%)$ and infant $(50 \%)$. Mortality occurred in $10(90 \%)$ of 11 patients with cardiac failure as the indication of ventilator and in $11(73.33 \%)$ patients who used ventilator $\leq 48$ hours.

Conclusion: Status epilepticus and shock was the most common reason for ventilation. Incidence of VAP as the complication of ventilator is relatively low. Relatively high mortality found in age group infants, patients with cardiac failure as indication of ventilator and in patient with short duration use of ventilator.
\end{abstract}

\section{Introduction}

Ventilator is one of life supporting and non-therapeutic device that is used to help the process of breathing in patients who cannot breathing normally on their own. ${ }^{1}$ Ventilator works by doing gas exchange of the respiratory system and helping the work of respiratory muscles that are paralysis to make it easier for the patients to breath. ${ }^{1}$ One of the main reason for Intensive Care Unit (ICU) admission is based on the needs of the patient to use ventilator. 2 The frequency of children using ventilator in Pediatric Intensive Care Unit (PICU) varies from 17-64\%.3-5 In Indonesia, there are $6,7-40 \%$ ventilator in children health service all around Indonesia. ${ }^{6}$

The use of ventilator in children is based on multifactorial factor such as cardiac failure, respiratory failure, shock, neurological problems, and multi-organ dysfunction syndrome. ${ }^{2}$ However, the use of ventilator is many needed in respiratory problem. ${ }^{7}$ The World Health Organization Statisfical Indormation System (WHOSIS) reported that respiratory infection is the second main reasons for morbidity and mortality among children under five in Indonesia. ${ }^{8}$

Although the use of ventilator as life-supporting device is unquestionable, there are still some other side effect for the patients from using ventilator, such as Ventilator Associated Pneumonia (VAP), atelectasis, barotrauma, etc. ${ }^{7}$ However, there are only few studies among Asian countries especially Indonesia regading the use of ventilator in PICU. The aim of this study was to describe the gender, age, indications of ventilator, 
length of use of ventilator, complication from ventilator, and outcome of children with ventilator in PICU Dr. Soetomo General Hospital, Surabaya.

\section{Methods}

A cross-sectional study conducted from June 2017 - October 2018. Study population was all pediatric patients from one-month old to 18 years old who were admitted to PICU Dr.Soetomo Hospital and treated with ventilator from January - December 2017. The inclusion criteria is patients with ventilator for at least 24 hours in PICU. Patients with incomplete medical record and patient who got discharge before the treatment is completed were excluded.

The following data were collected from secondary data of medical records: basic demographic profile (age and gender), clinical condition that become an indication for using ventilator, length of use of ventilator, complication of ventilator, and outcome of patients either discharge with better condition or expired. VAP was defined if patients on ventilation for more than 48 hours and had a fever more than $38^{\circ} \mathrm{C}$ with purulent secretion and other specific supporting examination such as culture of the sputum and thorax imaging. ${ }^{9}$

Data was entered in and statistical analysed was performed using Microsoft Excel. The categorical variables were expressed as frequency and percentage. This study was approved by Dr.Soetomo General Hospital Health Research Ethics Committee (0025/ KEPK/II/2018).

\section{Results}

During $1^{\text {st }}$ January until $31^{\text {st }}$ December 2017 , there were 133 patients who admitted in PICU Dr. Soetomo General Hospital and using ventilator. From 133 patients, 59 patients met the inclusion criteria. Male:female ratio was $1: 1.46$. The average age was $30 \pm 46$ months. The value of SD was high because of the large age range of children who admitted in PICU. The age was further divided in to five categories based on the normal range of respiratory rate of children, there are 1-12 months $(45,76 \%),>1-3$ years $(33,90 \%), 4-5$ years $(5,08 \%)$, $6-12$ years $(8,47 \%)$ and $13-18$ years $(6,78 \%)$.

The indication for ventilator was divided in to six categories, there are respiratory failure $(22,03 \%)$, cardiac failure $(16,95 \%)$, lowered level of consciousness $(1,69 \%)$, status epileptics $(28,81 \%)$, shock $(28,81 \%)$, and neuromuscular disease $(1,69 \%)$. Duration of ventilator was divided in to two categories, there are less than 48 hours $(25,42 \%)$ and more than 48 hours $(74,58 \%)$. There were only $4(6,78 \%)$ patients who developed VAP as a complication because of ventilator. However, we found 3 patients developed atelectasis during ventilation, but that was remain unclear whether atelectasis occurred due to the use of ventilator or because of other underlying disease.

The mortality rate among children using ventilator who met our inclusion criteria was relatively high $(67,80 \%)$. This might happen because uncompleted medical records in patients who recovered so they are excluded from this study. Distribution of outcome to demographic and clinical data of the patients were presented in Table 1.

Table 1. Distrobution of Outcome to Demographic and Clinical Data of the Patients

\begin{tabular}{|c|c|c|c|c|c|c|c|}
\hline & \multirow{3}{*}{ Variabel } & \multicolumn{4}{|c|}{ Outcome } & \multirow{2}{*}{\multicolumn{2}{|c|}{ Total }} \\
\hline & & \multicolumn{2}{|c|}{ Recovered } & \multicolumn{2}{|c|}{ Death } & & \\
\hline & & (n) & $(\%)$ & (n) & $(\%)$ & (n) & $(\%)$ \\
\hline \multirow[t]{2}{*}{ Gender } & Male & 9 & 36.00 & 16 & 64.00 & 25 & 100 \\
\hline & Female & 10 & 29.41 & 24 & 70.59 & 34 & 100 \\
\hline \multirow[t]{5}{*}{ Age Groups } & Infant (1-12 months) & 7 & 25.93 & 20 & 74.07 & 27 & 100 \\
\hline & Toddler (1-3 years) & 7 & 35.00 & 13 & 65.00 & 20 & 100 \\
\hline & Preschooler (4-5 years) & 1 & 33.33 & 2 & 66.67 & 3 & 100 \\
\hline & School age (6-12 years) & 3 & 60.00 & 2 & 40.00 & 5 & 100 \\
\hline & Adolescent(13-18 years) & 1 & 25.00 & 3 & 75.00 & 4 & 100 \\
\hline \multirow{6}{*}{$\begin{array}{l}\text { Indication for Initiation of } \\
\text { Ventilator }\end{array}$} & Respiratory Failure & 3 & 23.08 & 10 & 76.92 & 13 & 100 \\
\hline & Cardiac Failure & 1 & 10.00 & 9 & 90.00 & 10 & 100 \\
\hline & Lowered Level of Consciousness & 1 & 100.00 & 0 & 0.00 & 1 & 100 \\
\hline & Status Epileptics & 3 & 17.65 & 14 & 82.35 & 17 & 100 \\
\hline & Shock & 10 & 58.82 & 7 & 41.83 & 17 & 100 \\
\hline & Neuromuscular Disease & 1 & 100.00 & 0 & 0.00 & 1 & 100 \\
\hline \multirow[t]{2}{*}{ Ventilator Duration } & $<48$ hours & 4 & 26.67 & 11 & 73.33 & 15 & 100 \\
\hline & $>48$ hours & 15 & 34.09 & 29 & 65.91 & 44 & 100 \\
\hline \multirow[t]{2}{*}{ Ventilator Complication } & VAP & 3 & 75.00 & 1 & 25.00 & 4 & 100 \\
\hline & Without Complication & 16 & 29.09 & 39 & 70.91 & 55 & 100 \\
\hline
\end{tabular}




\section{Discussion}

We found that $57,63 \%$ of 59 patients who used ventilator in PICU were female. This result was quite different if compared to another published studies, as the percentage of male patients using ventilator that admitted in PICU is mostly higher than the percentage of female., ${ }^{40}$ This might happen due to differences in the amount of sample between this study and other published studies is quite far. However, we still didn't find another studies that show any factors that might influence gender differences with ventilator use.

In this present study we found that from 40 patients who died, $20(50 \%)$ of them were infant. Similar results were also found in other studies that found their mortality rate were highest in infant. ${ }^{11,12}$ Simon et al. (2015) in their study said that immune system and organ maturity in infant haven't perfectly formed. ${ }^{13}$ It might be one of the reasons why mortality rate was commonly found highest in infant.

The most common indication for using ventilator were status epileptics (28.81\%) and shock (28.81\%). Begum\&Kumar (2016) and Meligy et al (2017) also found that the most common indication of ventilator in their studies is because of neurological problem $(27.8 \%$ and $38.9 \%) .{ }^{11,14}$ However, several other studies presented different results with respiratory problem was the most common indication of using ventilator in PICU., 5, Different results might happen because as tertiary care hospital in East Indonesia, most cases referred to Dr. Soetomo General Hospital were more complex and severe. Mortality rate was highest in children with cardiac failure as their indication of ventilator $(90 \%)$. The use of ventilator in patients with cardiac failure was not for curative therapy, ventilator can help to maintain breathing in children with cardiac failure, but doesn't necessarily prevent progress and development of the underlying disease..$^{15}$

Most of the patients were using ventilator for $>48$ hours $(74.58 \%)$. Similar results also found in study from Anitha et al (2016) who presented that $67.59 \%$ patients were using ventilator for $>72$ hours. 16 Mortality rate between patients with ventilator support $\leq 48$ and $>48$ hours was not significantly different. Among 15 patients who used ventilator for $\leq 48$ hours, $73,33 \%$ of them were dead. It might because of patients with ventilator use $\leq 48$ hours is commonly came from another hospital or another room with severe and complication state and already had a low life expectancy.

The complication of ventilator among children with ventilator in PICU Dr. Soetomo General Hospital were relatively low if compared to other studies. There were only 4 from 59 patients who diagnosed with Ventilator Associated Pneumonia (VAP) (6.78\%). Of 4 patients, 1 patient had positive sputum culture results for gramnegative bacteria and 3 other patients had abnormalities such as lesion, infiltrate and opacity on their chest x-ray. Anitha et al (2016) reported that $21.1 \%$ patients developed VAP in India. ${ }^{16}$ Srinivasan (2015) et al and Casado et al (2011) also found relatively high incidents of VAP, that are $32 \%$ and $27.4 \% .{ }^{17,18}$ Different result might be due to several factors such as the underlying disease, gender, enteral nutrition and drug use. ${ }^{17}$ The limitation ofour study was because there are many medical records that are excluded because of incomplete records in medical records of the patients.

\section{Conclusion}

Most common indication for ventilation is status epileptics and shock, while the mortality rate was highest in patients with cardiac failure as their indication for using ventilator. Most of the patients using ventilator for $>48$ hours, and the mortality rate between patients with ventilator $\leq 48$ and $>48$ hours was not significantly different. We recommend further study to observe profile of patients using ventilator in PICU prospectively to get more accurate data and present more accurate charateristics.

\section{Conflict of Interest}

None declared

\section{References}

1. Mesiano G and Davis GM. Ventilatory Strategies in the Neonatal and Paediatric Intensive Care Units. Paediatric Respiratory Reviews. 2008; 9: 281-9.

2. Popat B and Jones AT. Invasive and Non-Invasive Mechanical Ventilation. Medicine. 2012; 40: 298-304.

3. Farias JA, Frutos F, Esteban A, et al. What is the Daily Practice of Mechanical Ventilation in Pediatric Intensive Care Units? A Multicenter Study. Intensive Care Medicine. 2004; 30: 918-25.

4. Wolfler A, Calderoni E, Ottonello G, et al. Daily Practice of Mechanical Ventilation in Italian Pediatric Intensive Care Units: A Prospective Survey*. Pediatric Critical Care Medicine. 2011; 12: 141-6.

5. Randolph AG, Meert KL, O'Neil ME, et al. The Feasibility of Conducting Clinical Trials in Infants and Children with Acute Respiratory Failure. American Journal of Respiratory and Critical Care Medicine. 2003; 167: 1334-40.

6. (RIFASKES) RFK. Laporan Akhir Riset Fasilitas Kesehatan Rumah Sakit 2011. Jakarta: Kementerian Kesehatan Republik Indonesia, 2012.

7. Silva DC, Shibata AR, Farias JA and Troster EJ. How is Mechanical Ventilation Employed in a Pediatric Intensive Care Unit in Brazil? Clinics (Sao Paulo, Brazil). 2009; 64: 1161-6.

8. Organization WH. Indonesia: WHO Statistical Profile. Geneva: World Health Organization, 2015.

9. Malisie RF. Kegawatan Respirasi pada Anak. In: Pudjiadi AH, Latief A and Budiwardhana N, (eds.). Buku Ajar Pediatri Gawat Darurat. Jakarta: Ikatan Dokter Anak Indonesia, 2011, p. 73-4.

10. Mukhtar B, Siddiqui NR and Haque A. Clinical Characteristics and Immediate-Outcome of Children Mechanically Ventilated in PICU of Pakistan. Pakistan journal of medical sciences. 2014; 30: 927-30.

11. Begum A, Shashikala and Kumar S. A Prospective Study on Clinical Profile and Outcome of Ventilated Children in a Pediatric Intensive Care Unit of a Tertiary Care Teaching Hospital, Telangana. The International Organization of Scientific Research Journal of Dental and Medical Sciences (IOSR-JDMS). 2016; 15: 13-7.

12. Bhori NS, Ghate SV and Chhajed PS. A Study of Mechanical Ventilation in Children. 2017. 2017; 4: 5.

13. Simon AK, Hollander GA and McMichael A. Evolution of the Immune System in Humans from Infancy to Old Age. Proceedings of the Royal Society B: Biological Sciences. 2015; 282: 20143085.

14. Meligy BS, Kamal S and El Sherbini SA. Mechanical Ventilation Practice in Egyptian Pediatric Intensive Care Units. Electronic Physician. 2017; 9: 4370-7.

15. Edwards JD, Kun SS, Keens TG, Khemani RG and Moromisato DY. Children with Corrected or Palliated Congenital Heart Disease on Home Mechanical Ventilation. Pediatric Pulmonology. 2010; 45: 645-9.

16. Anitha GFS, Lakshmi S, Shanthi S, Darlington CD and Vinoth S. Clinical Profile of Children Mechanically Ventilated in a Pediatric Intensive Care Unit of a Limited Resource Setting. 2016. 2016; 3: 4.

17. Srinivasan R, Asselin J, Gildengorin G, Wiener-Kronish J and Flori HR. A Prospective Study of Ventilator-Associated Pneumonia in Children. Pediatrics. 2009; 123: 1108-15.

18. Casado RJ, de Mello MJ, de Aragão RC, de Albuquerque Mde F and Correia JB. Incidence and Risk Factors for Health Care-Associated Pneumonia in a Pediatric Intensive Care Unit. Critical Care Medicine. 2011; 39: 1968-73. 